\title{
Desain dan Implementasi Sistem Informasi Akademik (Studi Kasus Fakultas Ilmu Agama Islam Universitas Islam Indragiri)
}

\author{
Muh. Rasyid Ridha1, Usman ${ }^{2}$, Dwi Yuli Prasetyo ${ }^{3}$ \\ Jurusan Sistem Informasi, Fakultas Teknik dan Ilmu Komputer, Universitas Islam Indragiri \\ Jl. Provinsi parit 1 Tembilahan Hulu, Tembilahan, Riau \\ E-mail: ${ }^{1}$ rasyid4sky@gmail.com, ${ }^{2}$ usmanovsky13411@yahoo.com, ${ }^{3}$ dwiyuliprasetyo@gmail.com
}

Masuk: 8 Juli 2014; Direvisi: 21 Juli 2014; Diterima: 12 Agustus 2014

\begin{abstract}
Information systems are running at the Faculty of Islamic Studies Islamic University Indragiri even though the academic data processing still employs a simple computerized system. The system mainly operates standard office (Microsoft Office Excel and Word) that allows a lot of errors in the processing of academic data. And this situation causes inefficiency in the academic services provided by the Faculty of Islamic Studies resulting in data search difficulty and a time waste in the making of the report. To solve these problems a new academic information system is needed so that any waste involving the processing of data can be reduced to provide satisfactory services to the users of the system. The design of the academic information system is illustrated in the Unified Modeling Language (UML).
\end{abstract}

Keywords: Academic, Information Systems, Unified Modeling Language (UML)

\begin{abstract}
Abstrak. Sistem Informasi yang berjalan di Fakultas Ilmu Agama Islam Universitas Islam Indragiri yang dalam pengolahan data akademiknya masih menggunkan sistem komputerisasi sederhana. Walaupun sudah didukung dengan komputer tetapi hanya memanfaatkan office standar (Microsoft Office Excel dan Word) sehingga memungkinkan banyak sekali kesalahan dalam pengolahan data akademik. Dan menyebabkan pelayanan akademik yang diberikan oleh Fakultas Ilmu Agama Islam menjadi kurang efisien, serta mengakibatkan kesulitan dalam pencarian data dan menyita waktu relatif lama dalam pembuatan laporan. Untuk membantu dalam menyelesaikan masalah tersebut perlu adanya suatu sistem informasi akademik yang baru agar setiap pekerjaan yang menyangkut pengolahan datanya dapat dikurangi tingkat kesalahannya serta dapat memberikan pelayanan yang memuaskan terhadap para pengguna sistem. Dalam perancangan sistem informasi akademik ini digambarkan ke dalam bentuk diagram UML (Unified Modelling Language).
\end{abstract}

Kata Kunci: Akademik, Sistem Informasi, Unified Modeling Language (UML).

\section{Pendahuluan}

Pemanfaatan IT dalam perguruan tinggi perlu mendapat perhatian yang lebih mengingat perannya dalam proses pengambilan keputusan manajerial ataupun keputusan-keputusan manajemen lainnya. Untuk meningkatkan efektivitas pencapaian penyelenggaraan ataupun pengelolaan perguruan tinggi, maka faktor-faktor yang berpengaruh pada efektivitas penerapan IT pada pengelolaan kelembagaan, terlebih khusus dalam hal administrasi akademik perlu diteliti lebih lanjut. Hal ini bertujuan agar proses manajemen akademik di perguruan tinggi menjadi lebih efektif dan efisien sehingga dapat menunjang pencapaian kinerja yang baik dari lembaga. Selanjutnya dengan memperhatikan hal-hal diatas, penelitian ini mencoba untuk memperoleh data yang cukup lengkap dan dapat dipercaya untuk menggambarkan tentang keadaan faktor-faktor yang terkait dengan Sistem Informasi Akademik dengan pemanfaatan IT terhadap kinerja perguruan tinggi dan dampaknya terhadap prestasi akademik mahasiswa. Data yang telah diperoleh juga dapat digunakan untuk mengembangkan Sistem Informasi Akademik yang dapat memberi dukungan pada setiap proses pelayanan akademik maupun pengambilan 
keputusan baik di lingkungan internal maupun yang terkait dengan lingkungan eksternal. Hal ini dipandang penting dalam rangka menghubungkan dinamika kebutuhan pengguna informasi dan dinamika perkembangan sistem informasi akademik sebagai penghasil informasi bagi keperluan pelayanan dan pengambilan keputusan.

Sistem Informasi yang berjalan di Fakultas Ilmu Agama Islam pada Universitas Islam Indragiri dalam pengolahan data akademiknya masih menggunakan sistem komputerisasi sederhana, artinya walaupun sudah didukung dengan komputer tetapi hanya memanfaatkan office standar (Microsoft Excel dan Microsoft Word) sehingga memungkinkan banyak sekali kesalahan dalam pengolahan data akademik. Hal ini dapat menghambat pelayanan akademik terhadap mahasiswa dan dosen sehingga menjadi kurang efisien, serta mengakibatkan kesulitan dalam pencarian data dan menyita waktu yang relatif lama untuk pembuatan laporan. Untuk membantu dalam pemecahan masalah tersebut perlu adanya sistem informasi yang baru agar setiap pekerjaan yang menyangkut pengolahannya dapat dikurangi tingkat kesalahannya serta dapat memberikan pelayanan yang lebih baik terhadap para pengguna Sistem Informasi Akademik. Perancangan sistem informasi ini menggunakan pemodelan UML.UML adalah suatu alat untuk memvisualisasikan dan mendokumentasikan hasil analisa dan desain yang berisi sintak dalam memodelkan sistem secara visual (Haviluddin, 2011). Sebagai alat bantu modelling dalam suatu pengembangan sistem, UML memiliki beberapa diagram yang mampu membantu pengembang mengkomunikasikan sistem yang akan dibuat. Diagram-diagram tersebut antara lain adalah use case, activity diagram, class diagram, dan sequence diagram. (Fitriani, 2011).

Dalam analisis dan perancangan sistem informasi ini, metode pengembangan sistem yang digunakan adalah metode pengembangan SDLC (System Development Life Cycle) serta menggunakan pendekatan prototype. Dalam proses pengumpulan datanya, metode yang digunakan adalah observasi, wawancara, dan studi literatur yang diperlukan untuk mendapatkan informasi dengan cara mengumpulkan data-data melalui buku-buku, literatur, makalah dan sumber-sumber lainnya yang berhubungan dengan masalah yang dibahas.

\section{Tinjauan Pustaka}

\subsection{Penelitian Terdahulu}

Menurut Indrayani (2011), pemanfaatan teknologi informasi dan komunikasi pada bidang layanan administrasi akademik di perguruan tinggi menjadi suatu kebutuhan, bukan hanya sekedar prestige atau lifestyle manajemen pendidikan tinggi modern. Namun dalam implementasinya, banyak kendala yang ditemui perguruan tinggi dalam menerapkan TIK dalam proses pengelolaan kelembagaan ini baik faktor teknis maupun non teknis. Menurut Tyas, dkk (2012) tujuan utama dari penelitian ini adalah pembuatan sistem informasi yang dapat digunakan untuk pendataan akademik di Lembaga Bimbingan Belajar Spectrum.

Metode yang diambil penulis yaitu dengan melakukan observasi, wawancara, studi pustaka, analisis, perancangan sistem, pembangunan sistem dan uji coba. Hasil dari penelitian ini adalah untuk memberikan kemudahan dalam proses pengolahan data akademik, seperti data siswa, data pembayaran, data guru, dan untuk mempermudah dalam proses pencarian data selain itu memiliki media penyimpanan yang lebih efektif dan lebih besar.

Dalam Implementasi Sistem Informasi Akademik Universitas Negeri Gorontalo (Lukum, 2013) dijelaskan bahwa implementasi sistem informasi akademik secara online di Universitas Negeri Gorontalo (UNG) belum berjalan sesuai dengan hakekat dan tujuan pengelolaan sistem informasi. Kebutuhan informasi umum semua unit UNG belum terpenuhi sedangkan resistensi yang dihadapi UNG dalam mewujudkan sistem online adalah sumber daya manusia, yang ditandai dengan rendahnya pemahaman tupoksi pada masing-masing bagian serta kurang memiliki keahlian dalam sistem informasi akademik terutama dalam mengoperasikan komputer.

Kurnia, dkk (2012) menjelaskan hasil penelitiannya menunjukan bahwa penggunaan sistem informasi akademik nilai siswa berbasis web telah mengakomodasi guru dan staff yang bertugas untuk dapat mengelola data-data nilai harian siswa dengan mudah melalui internet. 
Benisius (2013) menerangkan bahwa Universitas Halmahera sejak 2011 telah memiliki sistem informasi akademik berbasis teknologi informasi yang digunakan untuk menunjang pelayananpelayanan akademik seperti penginputan jadwal kelas, pencetakan presensi kelas, DRS-DHS dan lain-lain. Namun, sistem yang ada belum dilengkapi dengan kemampuan untuk mendeteksi kondisi tabrakan dalam penjadwalan sehingga kasus-kasus tabrakan masih dapat terjadi. Penelitian ini bermaksud mengembangkan suatu aplikasi yang mampu mendeteksi terjadinya tabrakan ruang, dosen dan mata kuliah pada semester yang sama, di samping itu aplikasi ini juga memberikan informasi rekap pemakaian ruang dan jumlah sks mengajar dosen.

Dalam penelitian oleh Hendriadi, dkk (2012) menyimpulkan bahwa 1) Tata kelola TI sistem informasi akademik pada Universitas Singaperbangsa Karawang sudah dilakukan walaupun masih belum berjalan secara optimal karena belum mencapai pada tingkat kematangan yang diharapkan. 2) Tingkat kematangan (maturity level) yang ada pada setiap proses TI yang terdapat dalam domain Plan an Organise (PO) rata-rata pada level 2,446 dan masih berada pada level 2 (repeatable but intuitive). 3) Proses tata kelola TI di UNSIKA telah memiliki pola yang berulangkali dilakukan dalam melakukan manajemen aktivitas terkait dengan tata kelola teknologi informasi, namun keberadaannya belum terdefinisi secara baik dan formal sehingga masih terjadi ketidakkonsistenan.

\subsection{Konsep Sistem Informasi}

Informasi dapat didefinisikan sebagai hasil dari pengelolaan data dalam suatu bentuk yang lebih berguna dan lebih berarti bagi penerimanya yang menggambarkan suatu kejadiankejadian atau event yang nyata $(\mathrm{fact}$ ) yang digunakan untuk pengambilan keputusan (Hartono, 2005). Sistem informasi secara teknis di definisikan sebagai sekumpulan komponen yang saling berhubungan, mengumpulkan, memproses, menyimpan, dan mendistribusikan informasi untuk menunjang pengambilan keputusan dan pengawasan dalam suatu organisasi. Sistem informasi menyiratkan suatu pengumpulan data yang terorganisasi beserta tatacara penggunaannya yang mencakup lebih jauh daripada sekedar penyajian (Ichwan, dkk, 2011).

Sistem informasi dapat didefinisikan sebagai sistem di dalam suatu organisasi yang merupakan kombinasi dari orang-orang, fasilitas, teknologi, media dan pengendalian yang ditujukan untuk mendapatkan jalur komunikasi penting, memproses tipe transaksi rutin tertentu, memberikan sinyal kepada manajemen dan yang lainnya, terhadap kejadian-kejadian internal dan eksternal yang penting dan menyediakan suatu dasar informasi untuk pengambilan keputusan (Hartono, 2005). Menurut Leitch dan Davis dalam (Hartono, 1999), sistem informasi adalah suatu sistem di dalam suatu organisasi yang mempertemukan kebutuhan pengolah transaksi harian, mendukung operasi, bersifat manajerial dan kegiatan strategi dari suatu organisasi dan menyediakan pihak luar tertentu dengan laporan-laporan yang diperlukan.

Sebuah sistem informasi merupakan kumpulan dari perangkat keras dan perangkat lunak komputer serta perangkat manusia yang akan mengelola data menggunakan perangkat keras dan perangkat lunak tersebut. Selain itu data juga memegang peranan yang penting dalam sistem informasi. Data yang akan dimasukkan adalah sebuah sistem informasi dapat berupa formulir-formulir, prosedur-prosedur dan bentuk data lainnya (Kristanto, 2008).

\subsection{Sistem Informasi Akademik}

Menurut Fadjar (2002:5), dalam Syachbana (2011), kata akademik berasal dari bahasa Yunani yakni academos yang berarti sebuah taman umum (plasa) di sebelah barat laut kota Athena. Nama Academos adalah nama seorang pahlawan yang terbunuh pada saat perang legendaris Troya. Pada plasa inilah filosof Socrates berpidato dan membuka arena perdebatan tentang berbagai hal. Tempat ini juga menjadi tempat Plato melakukan dialog dan mengajarkan pikiran-pikiran filosofisnya kepada orang-orang yang datang. Sesudah itu, kata academos berubah menjadi akademik, yaitu semacam tempat perguruan. Para pengikut perguruan tersebut disebut academist, sedangkan perguruan semacam itu disebut academia. Berdasarkan hal ini, inti dari pengertian akademik adalah keadaan orang-orang bisa menyampaikan dan menerima gagasan, pemikiran, ilmu pengetahuan, dan sekaligus dapat mengujinya secara jujur, terbuka, 
dan leluasa. Sistem Informasi Akademik merupakan suatu sistem yang dirancang dan dikembangkan sedemikian rupa dan terdiri dari sejumlah komponen seperti kurikulum, dosen, mahasiswa, silabus, KRS, KHS, nilai, dan lain sebagainya yang saling berinteraksi, saling bekerjasama membentuk suatu sistem (Anonim, 2012).

\subsection{Pendekatan Prototype}

Sebuah prototype adalah bagian dari produk yang mengekspresikan logika maupun fisik antarmuka eksternal yang ditampilkan. Konsumen potensial menggunakan prototype dan menyediakan masukan untuk tim pengembang sebelum pengembangan skala besar dimulai. Melihat dan mempercayai menjadi hal yang diharapkan untuk dicapai dalam prototype dengan menggunakan pendekatan ini, konsumen dan tim pengembang dapat mengklarifikasi kebutuhan dan intepretasi mereka (Simarmata, 2010). Membuat suatu prototype yang berbasis metodologi prototype yaitu melaksanakan tahapan-tahapan analisa, desain, dan tahapan implementasi secara bersamaan. Ketiga tahapan tersebut dilakukan secara berulang-kali sampai sistem itu diselesaikan. (Dennis, 2005).

\subsection{Analisis PIECES}

Analisa PIECES ini adalah analisa yang digunakan dalam pembuatan sistem informasi. Pada analisa PIECES ini adalah menganalisa data yang diperlukan dalam pembuatan sistem, dalam hal ini yaitu: Analisa Kinerja (Performance Analysis), Analisis Informasi (Information Analysis), Analisis Ekonomi (Economic Analysis), Analisis Pengendalian (Control Analysis), Analisis Efisiensi (Efficiency Analysis), dan Analisis Pelayanan (Service Analysis) (Hanif, 2007).

\section{Analisa dan Desain Sistem}

\subsection{Analisa Sistem}

Tahapan analisa sistem dilakukan setelah tahapan perencanaan sistem dan sebelum tahapan desain sistem. Tahapan analisa sistem merupakan tahapan yang kritis dan sangat penting karena kesalahan ditahap ini akan menyebabkan kesalahan di tahap selanjutnya. Pada sistem informasi akademik ini jenis analisis yang digunakan adalah analisis PIECES.

Untuk mengidentifikasi masalah, maka kita perlu melakukan analisis terhadap kinerja, informasi, ekonomi, keamanan, efisiensi dan pelayanan. Panduan ini dikenal sebagai Analisis PIECES (Perfomance, Information, Economic, Efficiency, Service).

\subsubsection{Analisis Kinerja (Perfomance Analysis).}

Berdasarkan pengamatan yang dilakukan pada Fakultas Ilmu Agama Islam, pada bagian administrasi, proses pengolahan dan penginputan data yang berhubungan dengan data akademiknya masih menggunakan personal komputer, kemudian data diarsip ke dalam bentuk dokumen. Hal ini dapat memperlambat dalam pencarian karena harus membolak balik arsip tersebut bila diperlukan.

\subsubsection{Analisis Informasi (Information Analysis).}

Dengan melakukan pencatatan data akademik dan kemudian diarsipkan ke dalam bentuk dokumen, akan mempersulit pengelola mengetahui informasi akademik.

\subsubsection{Analisis Ekonomi (Economic Analysis).}

Dalam hal ekonomi yang setiap tahun ajaran baru pihak pengelola harus membeli buku untuk melakukan pencatatan yang baru.

\subsubsection{Analisis Pengendalian (Control Analysis).}

Pengendalian atau kontrol dalam sebuah sistem sangat diperlukan keberadaannya untuk menghindari dan mendeteksi kesalahan yang terjadi, pada sistem informasi akademik yang terdapat pada Fakultas Ilmu Agama Islam ini sulit dilakukan pengendalian karena apabila 
terdapat duplikat data akademik akan diketahui apabila dilakukan pengecekan dokumen arsip yang membutuhkan waktu yang lama.

\subsubsection{Analisis Efisiensi (Efficiency Analysis).}

Sesuai pengamatan di bagian pengelola, mahasiswa melakukan transaksi dengan menyerahkan beberapa bentuk dokumen sebagai persyaratan dan kemudian diarsipkan. Apabila dokumen tersebut dibutuhkan maka harus melakukan bongkar arsip. Jika sewaktu-waktu data hilang, maka harus memintanya ulang kepada mahasiswa.

\subsubsection{Analisis Pelayanan (Service Analysis).}

Pelayanan yang diberikan oleh pihak pengelola dalam pelayanan akademik sudah baik. Tetapi pihak pengelola sulit dalam mencari nama-nama mahasiswa karena data yang ada masih berupa buku, sehingga harus dilakukan pencarian dengan membolak-balik dokumen untuk mendapatkan bukti mahasiswa sudah bertransaksi atau tidak.

\subsection{Perancangan Sistem}

Tahapan perancangan sistem informasi akademik ini merupakan alat bantu untuk mendesain sistem baru yang akan dibuat. Tujuannya adalah mengurangi kelemahan-kelemahan sistem sebelumnya yang terdapat pada Fakultas Ilmu Agama Islam Universitas Islam Indragiri. Gambar 1 menggambarkan sistem informasi akademik secara umum. Pada sistem ini aktifitasaktifitas yang terjadi di gambarkan dengan use case, kemudian sebagai pelakunya digambarkan dengan aktor. Aktifitas-aktifitas yang terjadi pada sistem informasi akademik ini keseluruhannya berhubungan dengan admin. Untuk user hanya mampu melakukan aktifitas login, mengganti password, input KRS, lihat data dan logout. Untuk operator hanya bisa melakukan aktifitas login, mengganti password, input nilai mahasiswa, lihat data dan logout.

Aktifitas yang terjadi pada diagram aktifitas pada Gambar 2 menunjukkan secara umum aliran kerja yang terdapat pada sistem informasi akademik yang akan dibangun. Pada aktifitas sistem informasi akademik ini dimulai dari proses login dengan mengisikan username dan password yang kemudian akan di validasi. Jika data benar maka akan menampilkan menu utama. Aktifitas-aktifitas yang terjadi setelah menampilkan menu utama yaitu aktifitas mengganti password, menambah data baru, merubah data, melihat data, mencetak berkas, dan menghasilkan laporan dalam bentuk dokumen. Aktifitas diakhiri dengan logout apabila akan mengakhiri aktifitas dengan menggunakan sistem informasi akademik ini.

Gambar 3 adalah gambar class diagram yang terdapat pada sistem informasi akademik ini. Dalam class diagram ini digambarkan proses awal adalah otentifikasi pengguna, selanjutnya aktifitas-aktifitas yang terdapat pada sistem informasi akademik ini dapat dilakukan sesuai dengan batasan otentifikasi yang sudah ditetapkan. Menu-menu aktifitas yang terdapat dalam sistem ini dapat digunakan berdasarkan kelas-kelasnya. Menu file dapat melakukan tambah data dengan menggunakan data master, kemudian mengelola data mahasiswa seperti tambah data mahasiswa yang mengakses tabel mahasiswa sebagai data master yang terdapat di dalam database yang digunakan oleh sistem informasi akademik ini. 


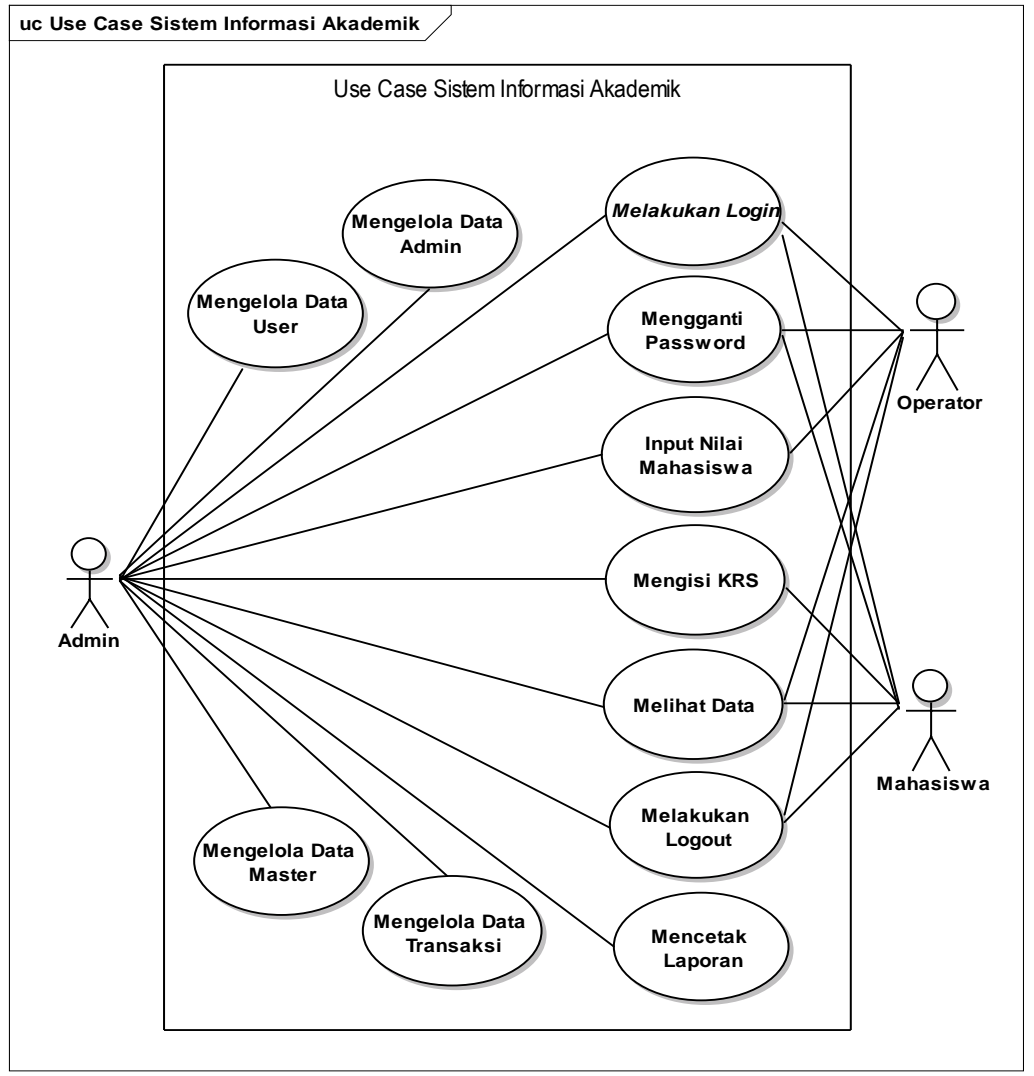

Gambar 1. Use Case Diagram Utama

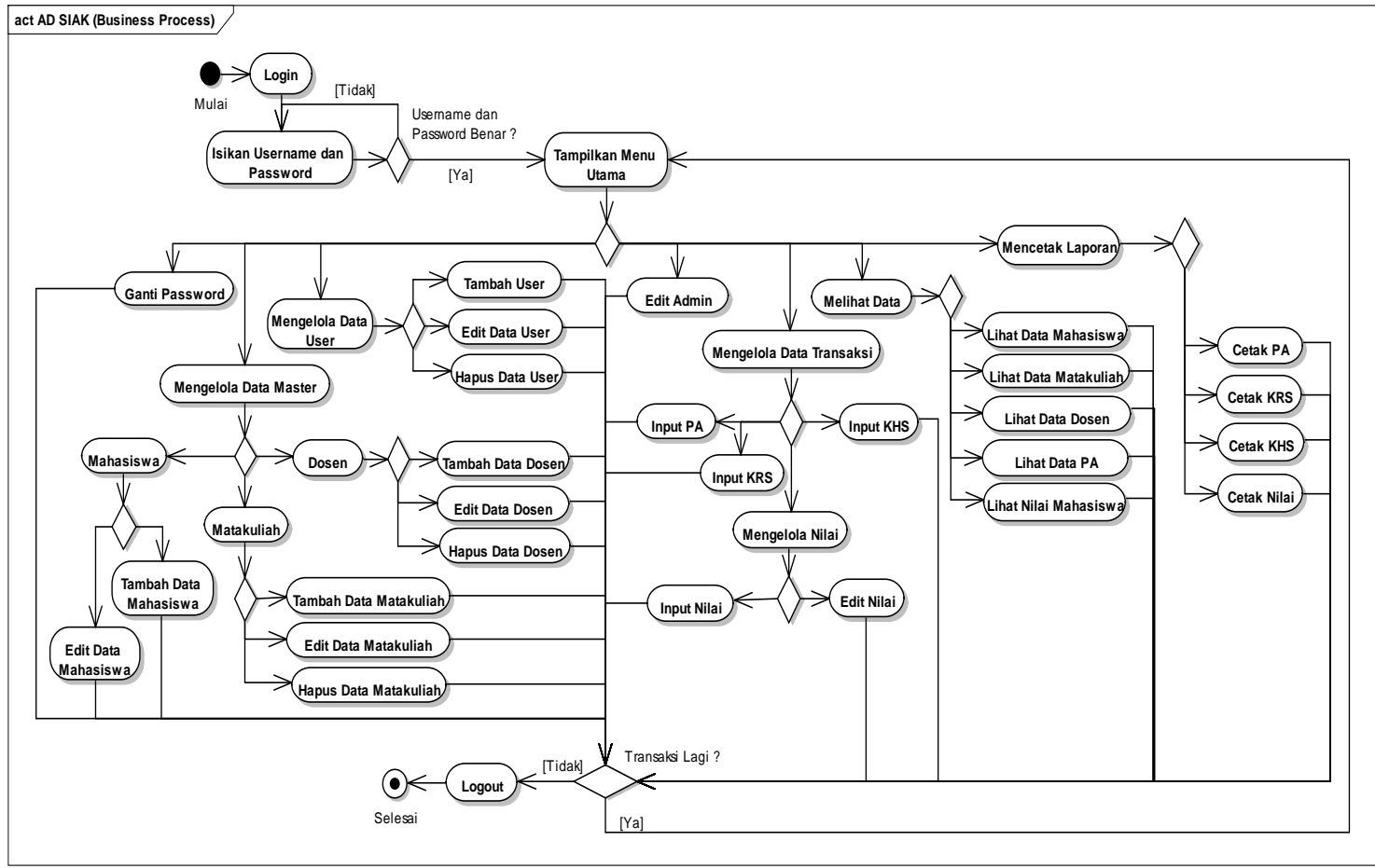

Gambar 2. Activity Diagram Utama 


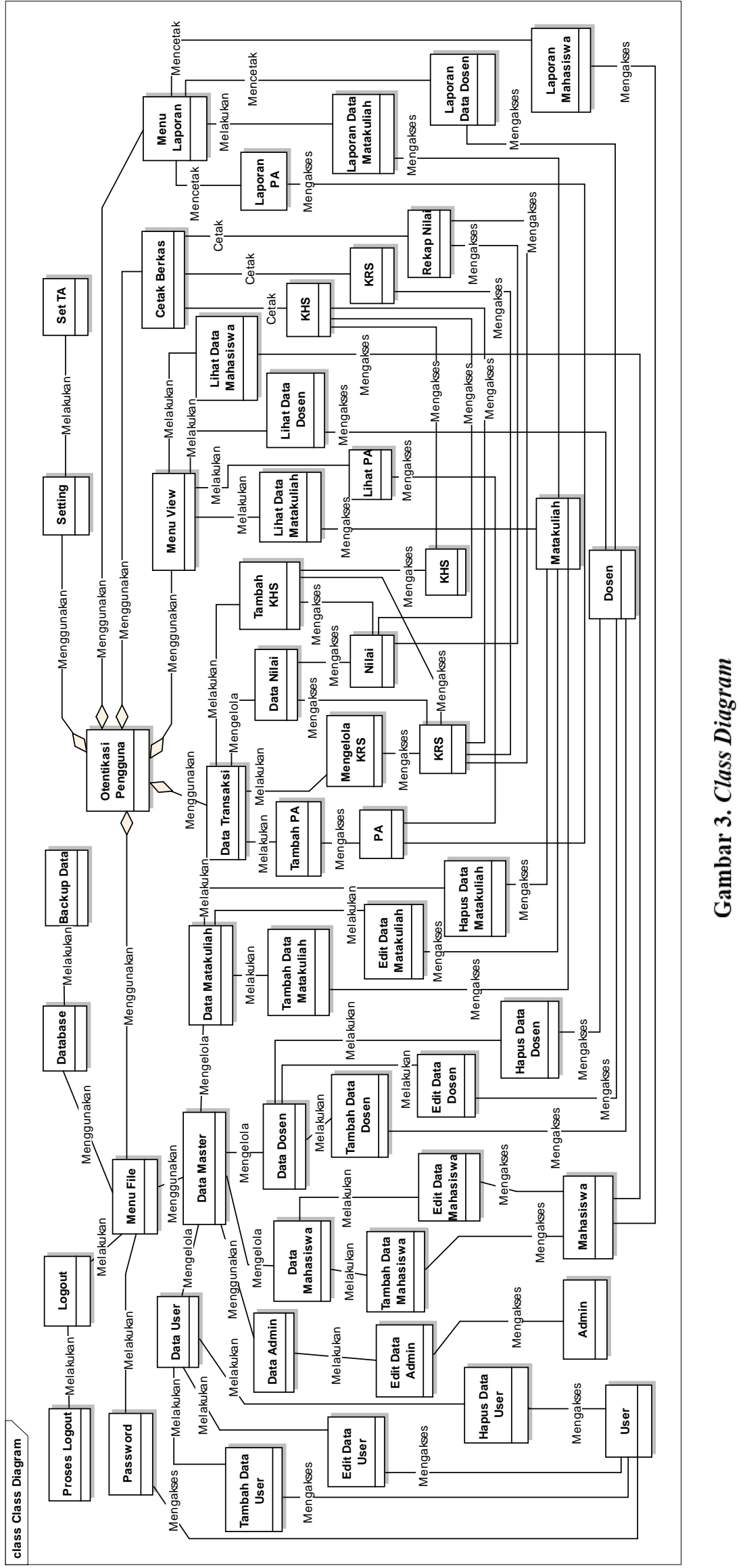




\section{Hasil dan Pengujian \\ 4.1. Implementasi Sistem}

Implementasi sistem merupakan tahapan yang akan membahas atau menceritakan sistem yang telah dibangun, sehingga akan diketahui bagaimana proses kerja dari sistem tersebut. Penjelasan-penjelasan dari setiap tampilan atau bentuk dari layar monitor sebagai interface antara user dengan sistem yang sudah dirancang pada aplikasi ini. Berikut ini merupakan penjelasan-penjelasan dari setiap user interface aplikasi.

Form input KRS adalah form yang digunakan untuk melakukan transaksi pengisian KRS. Pada transaksi ini user harus mengisikan NIM dan memilih atau mengisikan tahun akademik, semester, dan kelas. Kemudian memilih mata kuliah yang ditawarkan dengan cara meng-klik mata kuliah dan akan dipindahkan pada list mata kuliah yang diambil. Setelah itu pilih tombol simpan maka akan menampilkan lembar KRS yang baru dimasukkan. Jika terjadi kesalahan dalam memilih mata kuliah maka cukup tandai mata kuliah tersebut lalu tekan tombol batal, mata kuliah tersebut akan dihilangkan pada list KRS yang akan diambil. Form Input KRS dapat dilihat pada Gambar 4.

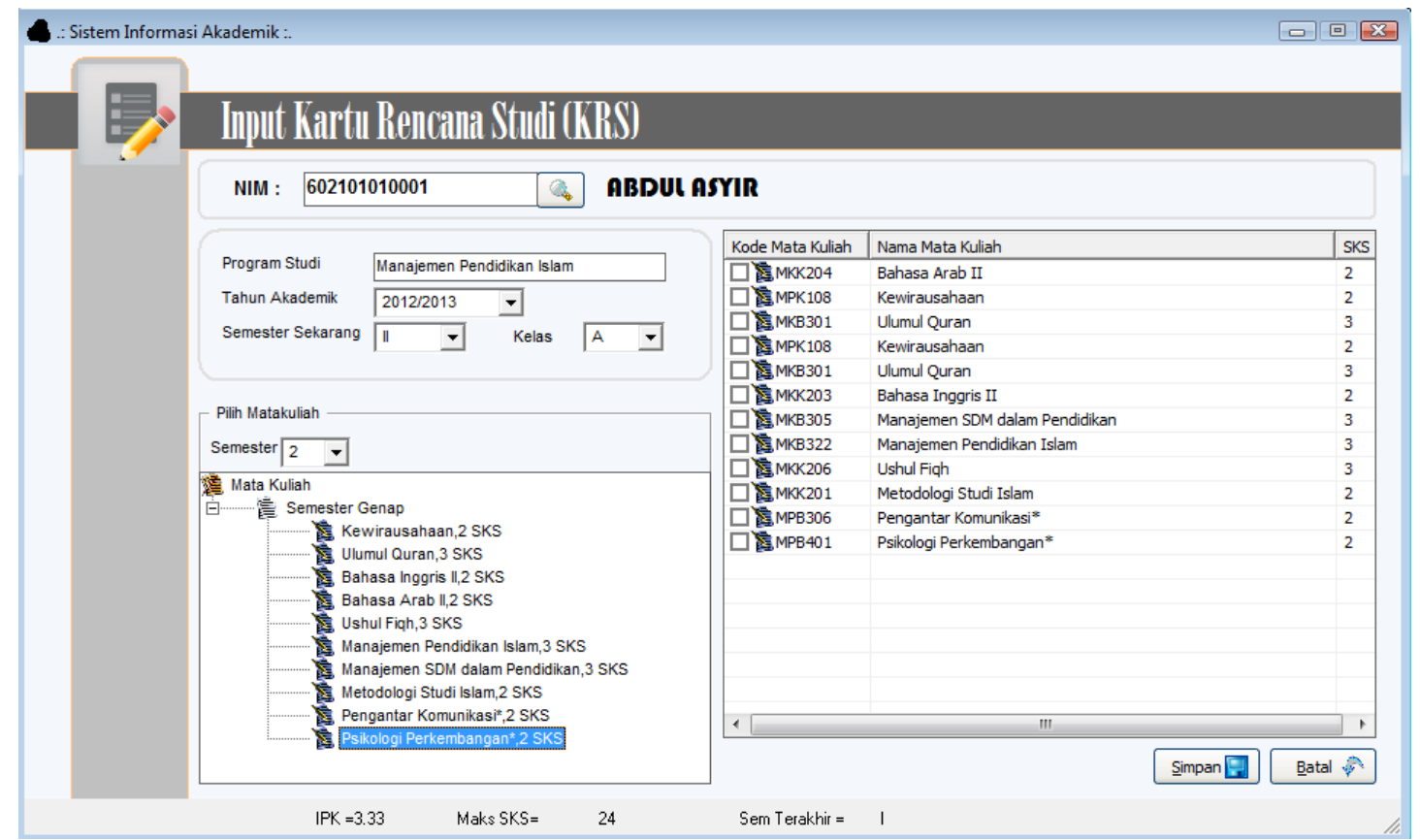

Gambar 4. Form Input KRS

Form input KHS adalah form yang digunakan untuk melakukan transaksi pembuatan kartu hasil studi (KHS). Proses transaksi yang dilakukan dalam input KHS ini adalah memilih tahun angkatan, prodi dan semester, kemudian cari data mahasiswa dengan menekan tombol cari, secara otomatis nomor KHS akan terisi, lalu pilih mahasiswa. Apabila mahasiswa pada semester tersebut sudah dimasukkan nilainya maka akan ditampilkan pada list KHS dimana IPK dan IP juga akan terlihat. Untuk melakukan proses input KHS maka cukup dengan meng-klik tombol Print. Form input KHS dapat dilihat pada Gambar 5.

Form input nilai adalah form yang digunakan untuk melakukan input nilai mahasiswa, yaitu dengan memasukkan NIM, semester, kelas dan dosen. Kemudian menekan tombol cari, lalu pilih mata kuliah yang akan dimasukkan nilainya. Dengan mengklik kanan pada mouse lalu pilih input nilai. Form input nilai dapat dilihat pada Gambar 6. 


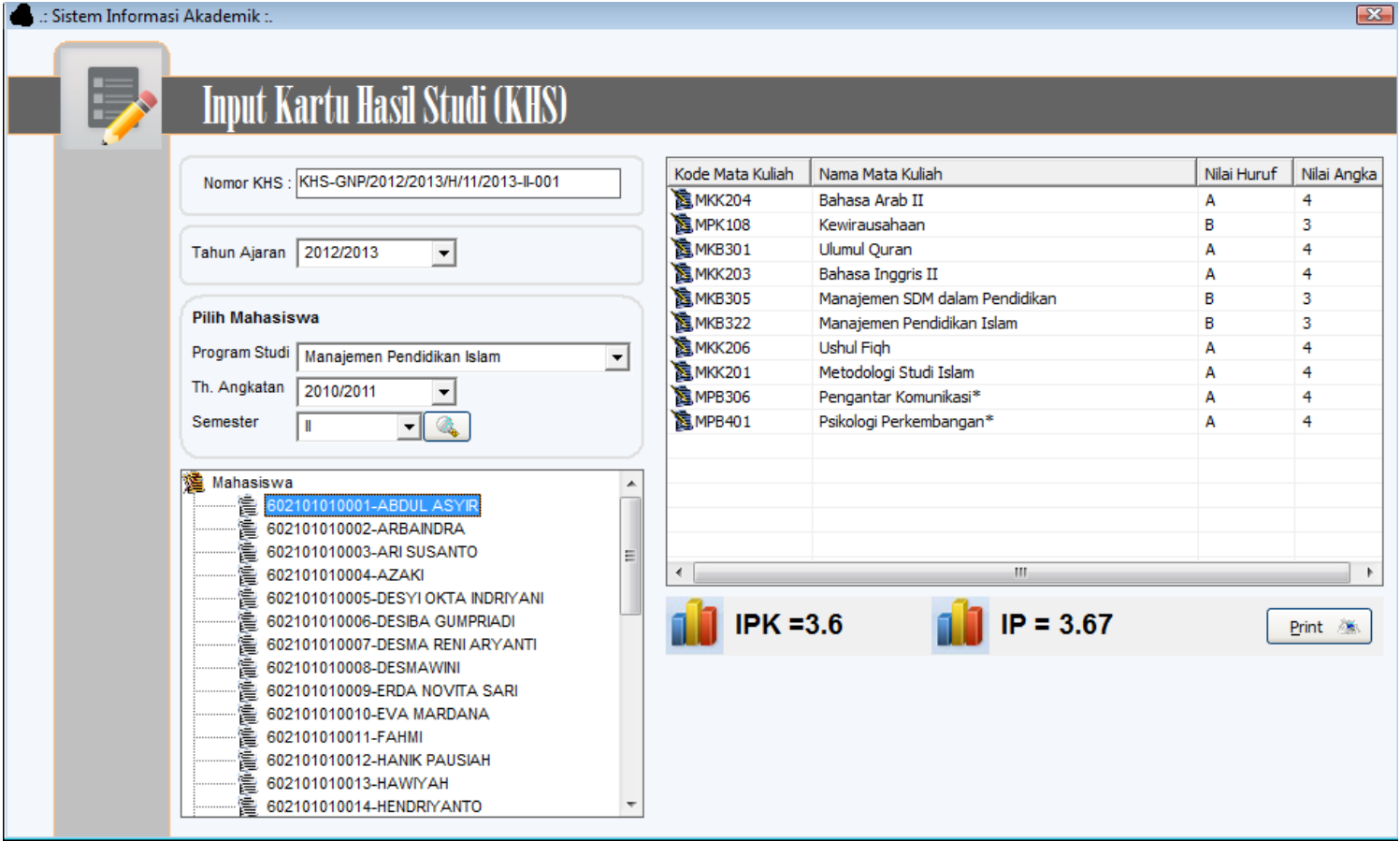

Gambar 5. Form Input KHS

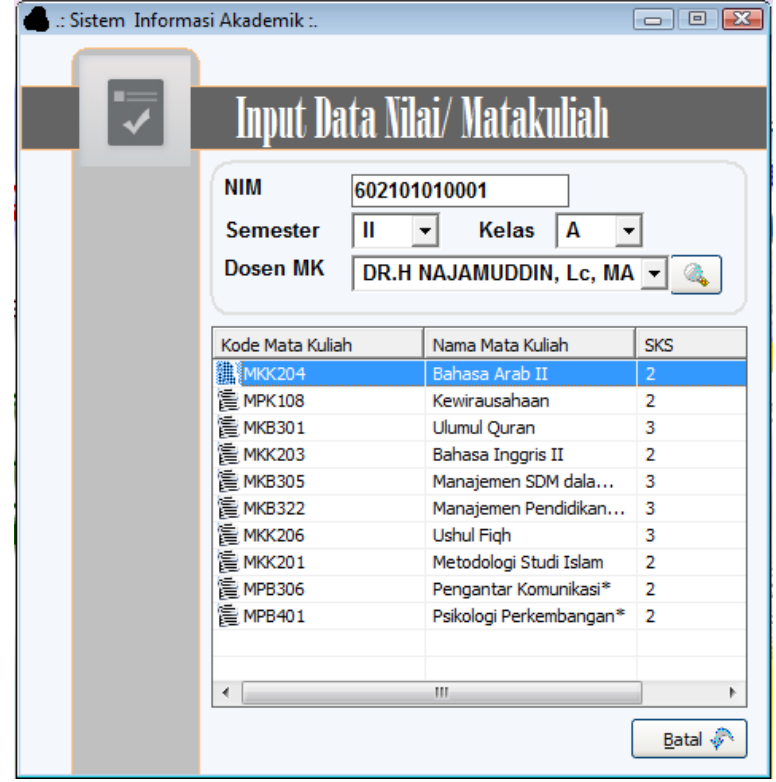

Gambar 6. Form Input Nilai

\subsection{Pengujian Sistem}

Untuk pengujian evaluasi hasil akhir pada sistem informasi akademik ini dilakukan agar diketahui bahwa aplikasi ini mampu menghasilkan informasi atau laporan yang benar dan sesuai dengan tujuan yang diharapkan. Pengujian dilakukan terhadap kemampuan sistem informasi akademik ini dalam melakukan operasi akademiknya. Pengujian ini dilakukan dengan menggunakan kuesioner terhadap pihak-pihak pengguna sistem informasi akademik ini. Untuk kepentingan pengguna ini diambil sampel calon pengguna sistem yaitu: a) Mahasiswa (15 orang), b) Dosen (7 orang) dan c) Karyawan/TU (3 orang).

Hasil uji reliabilitas mencerminkan dapat dipercaya dan tidaknya suatu instrumen penelitian berdasarkan tingkat kemantapan dan ketetapan suatu alat ukur dalam pengertian bahwa hasil pengukuran yang didapatkan merupakan ukuran yang benar dari sesuatu yang 
diukur. Dalam penelitian ini uji reliabilitas dilakukan dengan menggunakan software SPSS 15.0 for Windows.

\subsubsection{Correctness (Kebenaran) Uji-t Satu Sampel}

Dari Tabel 1 dan Tabel 2, Uji-t Satu Sampel ini menguji tingkat kebenaran dari sistem informasi akademik ini. Nilai uji statistik $t$ yang didapat $t=25.163$ dengan derajat kebebasan $=$ $\mathrm{n}-1=25-1=24$. Nilai $P$-Values (untuk 2-tailed) $=.000$ jelas lebih kecil dari $\alpha=0.05$, sehingga dapat disimpulkan bahwa tingkat kebenaran (correctness) sistem informasi akademik ini memenuhi atau dapat dipercaya/benar, atau lebih adalah tidak benar.

Tabel 1. One-Sample Statistics Correctness (Kebenaran)

\begin{tabular}{ccccc}
\hline & $\mathbf{N}$ & Mean & Std. Deviation & Std. Error Mean \\
\hline Correctness (Kebenaran) & 25 & 7.56 & 1.502 & .300 \\
\hline
\end{tabular}

Tabel 2. One-Sample Test Correctness (Kebenaran)

\begin{tabular}{|c|c|c|c|c|c|c|}
\hline 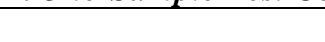 & \multicolumn{6}{|c|}{ Test Value $=0$} \\
\hline & \multirow[t]{2}{*}{$\mathbf{T}$} & \multirow[t]{2}{*}{ Df } & \multirow{2}{*}{$\begin{array}{l}\text { Sig. (2- } \\
\text { tailed) }\end{array}$} & \multirow{2}{*}{$\begin{array}{c}\text { Mean } \\
\text { Difference }\end{array}$} & \multicolumn{2}{|c|}{$\begin{array}{l}\text { 95\% Confidence Interval of the } \\
\text { Difference }\end{array}$} \\
\hline & & & & & Lower & Upper \\
\hline Correctness (Kebenaran) & 25.163 & 24 & .000 & 7.560 & 6.94 & 8.18 \\
\hline
\end{tabular}

\subsubsection{Reliability (Reliabilitas) Uji-t Satu Sampel}

Dari Tabel 3 dan Tabel 4, nilai uji statistik $t$ yang didapat $t=28.989$ dengan derajat kebebasan $=\mathrm{n}-1=25-1=24$. Nilai $P$-Values $($ untuk 2-tailed $)=.000$ jelas lebih kecil dari $\alpha=0.05$, sehingga dapat disimpulkan bahwa untuk tingkat reliabilitas (reliability) sistem informasi akademik ini memenuhi atau dapat dipercaya/benar.

Tabel 3. One-Sample Statistics Reliability (Reliabilitas)

\begin{tabular}{rrrrr}
\hline & N & Mean & Std. Deviation & Std. Error Mean \\
\hline Reliability (Reliabiilitas) & 25 & 10.68 & 1.842 & .368 \\
\hline
\end{tabular}

Tabel 4. One-Sample Test Reliability (Reliabilitas)

\begin{tabular}{lcrrrrr}
\hline & \multicolumn{1}{c}{ Test Value = 0 } \\
\cline { 2 - 6 } & T & Df & $\begin{array}{c}\text { Sig. (2- } \\
\text { tailed) }\end{array}$ & $\begin{array}{c}\text { Mean } \\
\text { Difference }\end{array}$ & $\begin{array}{c}\text { 95\% Confidence Interval of } \\
\text { the Difference }\end{array}$ \\
\hline Reliability (Reliabiilitas) & & 28.989 & 24 & .000 & 10.680 & Lower \\
\hline
\end{tabular}

\subsubsection{Integrity (Integritas) Uji-t Satu Sampel}

Dari Tabel 5 dan Tabel 6, Uji- $t$ Satu Sampel ini menguji tingkat integritas dari sistem informasi akademik ini. Dapat di lihat bahwa nilai uji statistik $t$ yang didapat $t=20.189$ dengan derajat kebebasan $=\mathrm{n}-1=25-1=24$. Nilai $P$-Values $($ untuk 2-tailed $)=.000$ jelas lebih kecil dari $\alpha=0.05$, sehingga dapat disimpulkan bahwa tingkat integritas (integrity) sistem informasi akademik ini memenuhi atau dapat dipercaya/benar, atau lebih adalah tidak benar.

Tabel 5. One-Sample Statistics Integrity (Integritas)

\begin{tabular}{rrrrr}
\hline & N & Mean & Std. Deviation & Std. Error Mean \\
\hline Integriti (Integritas) & 25 & 7.04 & 1.744 & .349 \\
\hline
\end{tabular}

Tabel 6. One-Sample Test Integrity (Integritas)

\begin{tabular}{|c|c|c|c|c|c|c|}
\hline & \multicolumn{6}{|c|}{ Test Value $=0$} \\
\hline & \multirow[t]{2}{*}{$\mathbf{T}$} & \multirow[t]{2}{*}{ Df } & \multirow{2}{*}{$\begin{array}{l}\text { Sig. (2- } \\
\text { tailed) }\end{array}$} & \multirow{2}{*}{$\begin{array}{c}\text { Mean } \\
\text { Difference }\end{array}$} & \multicolumn{2}{|c|}{$\begin{array}{l}\text { 95\% Confidence Interval of } \\
\text { the Difference }\end{array}$} \\
\hline & & & & & Lower & Upper \\
\hline Integrity (Integritas) & 20.189 & 24 & .000 & 7.040 & 6.32 & 7.76 \\
\hline
\end{tabular}




\subsubsection{Usability (Kegunaan) Uji-t Satu Sampel}

Dari Tabel 7 dan Tabel 8, Uji- $t$ Satu Sampel ini menguji tingkat kegunaan dari sistem informasi akademik ini. Nilai uji statistik $t$ yang didapat $t=16.433$ dengan derajat kebebasan $=$ n-1=25-1=24. Nilai $P$-Values (untuk 2-tailed) $=.000$ jelas lebih kecil dari $\alpha=0.05$, sehingga dapat disimpulkan bahwa tingkat kegunaan (usability) sistem informasi akademik ini memenuhi atau dapat dipercaya/benar, atau lebih adalah tidak benar.

Tabel 7. One-Sample Statistics Usability (Kegunaan)

\begin{tabular}{rrrrr}
\hline & N & Mean & Std. Deviation & Std. Error Mean \\
\hline Usability (Kegunaan) & 25 & 3.56 & 1.083 & .217 \\
\hline
\end{tabular}

Tabel 8. One-Sample Test Usability (Kegunaan)

\begin{tabular}{|c|c|c|c|c|c|c|}
\hline & \multicolumn{6}{|c|}{ Test Value $=0$} \\
\hline & \multirow[t]{2}{*}{$\mathbf{T}$} & \multirow[t]{2}{*}{ Df } & \multirow{2}{*}{$\begin{array}{l}\text { Sig. }(2- \\
\text { tailed) }\end{array}$} & \multirow{2}{*}{$\begin{array}{c}\text { Mean } \\
\text { Difference }\end{array}$} & \multicolumn{2}{|c|}{$\begin{array}{l}95 \% \text { Confidence Interval of } \\
\text { the Difference }\end{array}$} \\
\hline & & & & & Lower & Upper \\
\hline Usability (Kegunaan) & 16.433 & 24 & .000 & 3.560 & 3.11 & 4.01 \\
\hline
\end{tabular}

\section{Kesimpulan}

Berdasarkan rumusan masalah yang di uraikan sebelumnya, dapat ditarik beberapa kesimpulan sebagai berikut: (1) Pada sistem lama pengolahan data akademik masih dilakukan dengan menggunakan personal komputer. Pada sistem baru sudah menggunakan sistem terkomputerisasi. (2) Pada sistem lama masih sering terjadi kesalahan dalam pengolahan data akademik, pada sistem yang baru sudah mengurangi tingkat kesalahan pada sistem yang lama. (3) Pada sistem lama proses input data akademik masih dilakukan berulang-ulang sehingga membutuhkan waktu yang lama dalam pelayanan akademik. Pada sistem yang baru mampu mengurangi input data yang dilakukan berulang-ulang. (4) Pada sistem lama juga masih sulitnya menemukan data karena penyimpanan masih dalam bentuk dokumen, pada sistem baru sudah menggunakan database. (5) Kerangkapan data juga sering terjadi pada sistem lama, kemudian pada sistem yang baru kerangkapan data tersebut dapat diminimalkan. Begitu juga tempat penyimpanan data masih tidak konsisten pada sistem lama sementara sistem yang baru sudah menggunakan database.

\section{Referensi}

Anonim. 2012. Konsep Dasar Merancang Jadwal Perkuliahan Terintegrasi Dengan Sistem Informasi Akademik, (Online), (edukasi.kompasiana.com/2012/05/21/konsep-dasarmerancang-jadwal-perkuliahan-terintegrasi-dengan-sistem-informasi-akademik464713.html, diakses pada tanggal 19 Februari 2013).

Benisius. 2013. Implementasi Algoritma First In First Served (FIFS) Pada Sistem Penjadwalan Perkuliahan (Studi Kasus Di Direktorat Akademik Universitas Halmahera). Jurnal UNIERA Vol 2 No 2.

Dennis, Alan, et al. 2005. Systems Analysis and Design with UML Version 2.0 an ObjectOriented Approach, US: John Wiley \& Sons, Inc.

Fitriani, N. 2011. Rancang Bangun Sistem Informasi Akademik Berbasis Web (Studi Kasus: Yayasan Pesantren Tarbiyah Nurul Ma' Arif Serang Banten). Jakarta. Program Studi Sistem Informasi Universitas Islam Negeri Syarif Hidayatullah.

Hanif, Al Fatta. 2007. Analisa dan Perancangan Sistem Informasi untuk Keunggulan Bersaing Perusahaan dan Organisasi Modern. Yogyakarta: ANDI

Hartono, Jogianto. 1999. Analisis dan Desain. Yogyakarta: ANDI.

Hartono, Jogianto. 2005. Pengenalan Komputer. Yogyakarta: ANDI.

Haviluddin. 2011. Memahami Penggunaan UML (Unified Modelling Language). Samarinda: Jurnal Informatika Mulawarman Vol 6 No 1. 
Hendriadi, A.A, dkk. 2012. Pengukuran Kinerja Sistem Informasi Akademik dengan Menggunakan Kerangka Kerja Cobit 4.1 pada Domain Plan and Organise Di Universitas Singaperbangsa Karawang. Majalah Ilmiah Solusi Unsika Vol 10 No 22.

Ichwan, M. Dkk, 2011. Penerapan Framework Federal Deposit Insurance Corporation Enterprise Architecture (FDIC EA) pada Sistem Informasi Akademik, Jurnal Informatika Vol 2 No 3.

Indrayani, Etin. 2011. Pengelolaan Sistem Informasi Akademik Perguruan Tinggi Berbasis Teknologi Informasi dan Komunikasi (TIK). Jurnal Penelitian Pendidikan.

Kurnia, Tedi. 2012. Perancangan Sistem Informasi Akademik Nilai Siswa Berbasis Web. Garut: Jurnal Algoritma.

Kristanto, Andri. 2008. Perancangan Sistem Informasi dan Aplikasinya. Yogyakarta: Gava Media.

Lukum, A. 2013. Implementasi Sistem Informasi Akademik Universitas Negeri Gorontalo. Jurnal Entropi.

Simarmata, Janner. 2010. Rekayasa Perangkat Lunak. Yogyakarta: Andi

Syachbana. 2011. Sistem Informasi Akademik Berbasis Multimedia Pada Lembaga Pendidikan Palembang Technology. Jurnal Teknologi dan Informatika (TEKNOMATIKA)

Tyas W, Kristin. Dkk. 2012. Pembangunan Sistem Informasi Akademik Lembaga Bimbingan Belajar Spectrum. Surakarta: Jurnal Speed. 